\title{
Le Moindre Geste ou \\ Infância em Cevennes por volta de 1960
}

Marlon Miguel*

\begin{abstract}
RESUMO: O presente artigo busca analisar a noção de gesto tomando como base teórica o trabalho de Walter Benjamin. Usaremos ainda a reflexão de Fernand Deligny e o filme feito por ele intitulado Le moindre geste, de 1971. Buscamos investigar no artigo uma certa concepção de produção artística, derrotada historicamente, que vem desde correntes menores e vanguardistas da União Soviética, passando pela Alemanha e chegando à França dos anos 1960. Tais concepções punham a arte a serviço de uma liberação e emancipação do humano de forma radicalmente anti-normativa. A partir de algumas figuras-chave, analisaremos então a relação entre arte, pedagogia e patologia.
\end{abstract}

PALAVRAS-CHAVE: Benjamin, gesto, Fernand Deligny

\footnotetext{
* Marlon Miguel é doutorando em Artes Plásticas na Universidade Paris 8 (em cotutela com o Departamento de Filosofia da Universidade Federal do Rio de Janeiro) e professor (ATER) do Departamento de Artes Plásticas da Universidade Paris 8. E-mail: marlonmiguel@gmail.com
} 
ABSTRACT: The present paper aims to analyze the notion of gesture taking as starting point the theoretical work of Walter Benjamin. We will also follow some ideas of Fernand Deligny, as well as his film Le moindre geste, made in 1971. We shall investigate in the paper a certain conception of art creation, which was historically defeated. This conception comes from USSR, passes through Germany and arrives in France in the 1960s. It linked art to a radical anti-normative task of liberation and emancipation of the human being. Using some key-thinkers, we will analyze the relationship between art, pedagogy and pathology.

KEYWORDS: Benjamin, gesture, Fernand Deligny

\begin{abstract}
Cem outros lugares, eis o que é preciso tramar. A existência de uma criança autista só pode se tramar na trama de uma existência muito cotidiana, aqui e ali, de alguns indivíduos. [...] Comunicação, relação, transmissão. Todas estas palavras em "ão", é preciso filtrar e refiltrar o que as impregna de poluição cultural. O mínimo gesto pode ser um sinal para uma criança que vive fora deste uso da palavra em nós arraigado. Eu escrevi: para e não: à. Tratar-se-ia de uma arte de viver?

-- Fernand Deligny, Nous et l'innocent (Le moindre geste peut faire

signe)
\end{abstract}

É preciso, por outro lado, aceitar que o que é percebido do ponto de ver é em primeiro lugar o que nos ocorre por inadvertência. Seria mesmo possível falar de "pura inadvertência", como se a sua legitimidade pudesse assim ser estimada.

-- Fernand Deligny, Le croire et le craindre

\title{
1. I. Orel, Rússia, por volta de 1915; Capri, Itália, 1924; Berlim, Alemanha, 1928
}

É a Walter Benjamin que Asja Lacis recorre necessitando escrever um texto programático estético-político para seu projeto de teatro infantil. Trata-se de pensar, através do teatro, como 
educar crianças segundo os preceitos da consciência de classes. Ao contrário do que se poderia esperar de tal texto, Benjamin avança teses contra todo o tipo de ideologização da criança, buscando ao contrário pensar a emancipação desde os primeiros anos de infância. A primeira questão apontada por Benjamin é que a palavra, o discurso não exerce nenhum poder - ou mais precisamente, violência, Gewalt - sobre a criança: a palavra, o blablablá, é a "segurança estúpida do parlamentarismo e dos adultos nele confinados". (BENJAMIN, 1977, p. 763) É possível fazer crianças repetirem por todo o país frases do programa revolucionário, mas como educá-las de modo que em dez ou vinte anos elas ajam segundo esse programa? Contrariamente à educação burguesa, que insiste em uma pedagogia da repetição e em métodos psicologizantes, a educação proletária desenvolve um contexto (uma moldura, Rahmen), um campo objetivo (ein sachliches Gebiet) no qual se educa. Se a educação burguesa erige uma ideia que será a norma segundo a qual a educação se orienta, o modelo educativo proletário fabricaria um campo onde se ornamenta. Na proposição de Lacis e Benjamin, esse campo objetivo, para crianças entre quatro e quatorze anos, seria o teatro proletário infantil.

Contrariamente ao teatro burguês, a representação não é o objetivo verdadeiro desse trabalho coletivo. A representação acontece como por inadvertência (ou por engano, aus Versehen). 0 que interessa, diz Benjamin, são as tensões que aparecem e encontram soluções durante o processo. Dessa forma, o motor da educação não é uma "direção moral", tampouco pedagógica no sentido tradicional de uma "lição", mas a tensão coletiva infantil trabalhada de forma longa e por ela mesma.

Se por um lado, esse coletivo infantil está em vias de formação, por outro, é importante para a coletividade geral observar a criança - pois o coletivo infantil é capaz de liberar as forças mais potentes e sobretudo as mais atuais. Para o educador-diretor, a observação e não a suposta superioridade do saber (do pedante, do Besserwisser) é o gênio da educação.

A observação - e aqui se inicia a educação - torna cada ação e gesto infantil sinais. Não, como gostaria o psicólogo, um sinal do inconsciente, de latências, de recalques e censuras, mas sinal vindo de um mundo no qual a criança vive e ordena... [...] Uma "doutrina dos sinais" não é uma simples maneira de falar. Quase todo gesto infantil é ordem e sinal. [...] A tarefa do educador consiste em resgatar os sinais infantis do perigoso reino da magia da pura imaginação conduzindo-os ao poder executivo sobre os materiais [...]. Nós sabemos - para citar unicamente a pintura - que o gesto infantil é também essencial nessa atividade. Konrad Fiedler foi o primeiro 
a mostrar em seus Escritos sobre a arte que o pintor não é um indivíduo dotado de uma visão mais naturalista, mais poética, mais exaltada do que outros, mas um homem que, quando o olho paralisa, vê de mais perto com a mão; um homem que transfere a inervação receptiva dos músculos da visão à inervação criadora da mão. A relação exata entre inervação criadora e receptividade define o gesto infantil. [...] A improvisação reina; ela é o estado a partir do qual os sinais, os gestos sinalizadores virão à tona. Se a apresentação, ou o teatro, sintetiza esses gestos, ela o faz justamente porque ela possui a singularidade do imprevisto, no qual os gestos infantis encontram seu espaço próprio. As "performances prontas" extraídas de crianças não podem de forma alguma ser comparadas à autenticidade das improvisações [...] A performance infantil busca não a "eternidade" dos produtos, mas a "instantaneidade" do gesto. O teatro, enquanto arte do efêmero, é a arte da criança. (BENJAMIN, 1977, p. 766-767)

Benjamin desenvolve assim uma série de ideias-chave: o gesto é menos ligado à palavra do que ao corpo, ele é ligado à instantaneidade (não tem, pois, sentido prévio); aparece, através do gesto, uma "doutrina dos sinais"; a educação é não um modelo normativo, mas um contexto onde se ornamenta; além disso a educação segue um modelo emancipativo e bidirecional: o educador-diretor fabrica o contexto, cria um espaço, mas ele desenvolve sua prática em função do que acontece après coup, ele não é senhor da situação, mas aprende igualmente com ela; a situação a se fabricar é essencialmente uma situação de jogo, de brincadeira; enfim, o objetivo dessa prática não é o produto final, mas se este surge, então acontece "por inadvertência". Duas séries de questões emergem: 1. o que o educador aprende observando atentamente a criança e qual a sua função? 2. o que significa essa instantaneidade e ausência de sentido prévio do gesto, e qual a sua relação com (e o que seria) uma doutrina dos sinais?

1. É preciso notar que o teatro é para a criança o "fogo no qual jogo e realidade se fusionam". (BENJAMIN, 1991a, p. 765) Além disso, o teatro, seguindo a definição de Benjamin e Lacis, promove uma "liberação ou emancipação (Entbindung) do jogo". (BENJAMIN, 1991a, p. 768)' As apresentações ou improvisações são um "intervalo criador" (schöpferische Pause) no qual o educador atento aprende com o gesto da criança no palco. E, por fim, a infância se realiza no jogo, mas dessa forma é toda a coletividade que sai ganhando: "o sinal secreto do porvir é o efeito revolucionário que se exprime através do gesto infantil". (BENJAMIN, 1991a, p. 769) A função do educador é assim de fabricar o espaço e de liberar tanto ele mesmo quanto a criança da imaginação. Há uma concatenação feita por Benjamin entre ideologia, magia e pura 
imaginação. Aquele que imagina, diz Bruno Tackels comentando Benjamin, é um ser confinado, pois a imaginação é uma faculdade de pura receptividade e pura passividade: a imaginação precisa ser transformada. (TACKELS, 2000, p. 75) Imaginar significa se representar imagens conhecidas previamente - significa pré-ver. A forma de liberar (erlösen) a imaginação se dá através do trabalho sobre a matéria (Stoffen), ou seja, insistindo sobre a mão, o corpo, o gesto. Trata-se pois dessa inervação da mão da qual fala Benjamin. Há assim uma passagem da visão e da imaginação ao corpo - autoapropriação do corpo - e ao gesto. Nessa passagem, é o educador igualmente que interrompe sua própria imaginação e assim a ideologia. Não cabe mais a ele dar as premissas do que se desenvolverá - e por isso há um "intervalo criativo", onde pode surgir algo inesperado, sem sentido prévio: trata-se assim de criação em seu sentido forte. É o educador que aprenderá então com o que poderá surgir.

2. O que interessa Benjamin no teatro é essa arte do efêmero, da cristalização do sentido no instante. O gesto pode sem dúvida ter um sentido ou produzir um sentido, mas seu aspecto essencial não reside aí. A potência do gesto está justamente no fato de que ele não pode ser completamente significado e ao contrário destrói a significação conhecida. Nesse sentido o gesto sinaliza algo, ou seja, ele (re)ordena o real; o gesto é talvez significante, mas não é necessariamente dotado de significação. Trata-se de um "signo para" (fazer algo, que incita a algo, que incita o agir) e não "signo a" (signo a alguém, visando uma comunicação). O gesto é imediatamente uma atividade e não uma comunicação, tampouco um produto - o produto seria uma série de signos/sinais ordenados e formalizados, uma série de gestos coreografados, dirigidos, mis en forme / en scène. A proposição de uma doutrina dos sinais, que não chegou a ser desenvolvida por Benjamin, seria o projeto de tal definição do conceito de signo e de suas consequências práticas. Essa doutrina se ligaria à teoria mais geral do nome e da semelhança em Benjamin e diria sem dúvida respeito a uma teoria do corpo.

A noção de gesto aparece então aqui entre duas noções fundamentais: a de "inervação" e a de "espaço de jogo" (Spielraum). A primeira, uma noção técnica importada da medicina, aparece de forma importante na versão francesa do texto sobre a obra de arte, especialmente na longa nota do parágrafo VI - as revoluções, dizem Benjamin, são "inervações do elemento coletivo" (BENJAMIN, 1991, p. 149) e tal como a criança tenta alcançar com sua mão a lua, é a humanidade mesma que busca às vezes o impossível na inervação. Em todo o caso, o que 
está em jogo é a passagem da "primeira técnica" (domínio da natureza) à "segunda técnica" (distanciação, por um lado, mas harmonização, por outro, com a natureza), ou seja, a abertura do homem à sua própria humanidade. O cinema ocupa aqui um lugar privilegiado, mas a aparição dessa "segunda técnica" não é possível segundo Benjamin senão através do jogo. (BENJAMIN, 1993, p. 148) Nos Paralipomènes de la première version do texto sobre a obra de arte, Benjamin afirma o seguinte:

O gestus de Chaplin não é de forma alguma a de um ator de teatro. Ele não agüentaria no palco. Sua significação excepcional reside no fato que o conjunto de gestos - considerado tanto do ponto de vista corporal quanto espiritual - é "reunido" mecanicamente na estrutura do filme. Eis a novidade do gestus de Chaplin: ele decompõe o movimento expressivo do homem em uma série de inervações íntimas. (BENJAMIN, 1993, p. 175-176)

Da mesma forma que o aprendizado do adulto com o gesto da criança era com esse gesto desconhecido e fabricado - não intencionalmente, mas no jogo improvisado -, o cinema permite graças à montagem um efeito similar. Nos dois casos, trata-se de uma forma outra do humano, atualização do humano; trata-se do gesto puro e mínimo, le moindre geste, antes de sua significação e de seu aprisionamento. Esse gesto antes desconhecido aparece enquanto força de abertura, fabricação e descoberta do humano - eis o elemento revolucionário, signo do porvir que se apresenta no gesto. Tanto no teatro infantil, quanto no cinema, é esse espaço de jogo, não a previsão e a vontade do produto final, que permitirão ao gesto de surgir - ou seja, não um modelo humano prévio, uma forma de se movimentar que conhecemos e imitaremos, não o exemplar e normativo, mas uma experimentação da corporeidade humana que nos faz descobrir algo de novo e imprevisível. O espaço de jogo é fabricado a partir da porosidade dos espaços que se tornam palcos de devires possíveis:

a arquitetura [de Nápoles] é porosa como essa pedra. Construção e ação se fundem uma na outra em pátios, arcadas e escadas. Neles se preserva o espaço de jogo que torna possível seus devires em um palco de novas constelações imprevisíveis. Evita-se o definitivo, o definido. Nenhuma situação aparece tal como ela é, ou eternamente planejada, nenhuma forma pretende que "assim seja e não de outra maneira". [...] Não se encontra a porosidade sozinha na indolência do artesão do sul, mas sobretudo na paixão pela improvisação. O espaço e a ocasião desta precisam em todo caso permanecer preservados. (BENJAMIN, 1991b, p. 309-310) 


\section{Intermezzo: Poltava, Ucrânia, por volta de 1920. A Colônia Gorki de Anton Semenovych Makarenko}

Vocês com certeza já perceberam várias vezes como pode faltar à coletividade infantil, ou à multidão, a capacidade de orientação. O homem vê o que se encontra debaixo do seu nariz, mas não o que se encontra nas suas costas. Essa capacidade de sentir o que há em sua volta, que the cerca, essa capacidade de sentir também tudo o que você não vê, o que ocorre em outros cômodos, sentir o tom da vida, o tom do dia, essa aptidão a se orientar, ela se educa dificilmente. É preciso usar todas as suas energias e sempre se lembrar que nós devemos educar essa capacidade de orientação. [...] O verdadeiro cidadão soviético deve ressentir de maneira quase inconsciente e com todos os seus nervos o que acontece no seu entorno.

-- Makarenko, A colônia Gorki

Eis então um novo tema de nossas preocupações. Após termos chegado à estética como o resultado do estilo, como a marca exterior do estilo, nós passamos a examiná-la como um fator educativo em si. Eu não poderia Ihes enumerar todas as normas de uma vida bela, mas ele deve o ser, absolutamente. Uma vida bela para as crianças não o é necessariamente para os adultos. As crianças possuem seu próprio tipo de emotividade, sua maneira de exprimir os movimentos da alma, e a beleza da coletividade infantil não pode ser a mera reprodução daquela da coletividade adulta. Tomemos como exemplo o jogo: o jogo deve figurar absolutamente na coletividade infantil. Uma coletividade infantil que não brinque não será uma verdadeira coletividade infantil. O jogo não consiste somente em correr atrás de uma bola em um campo, mas é um jogo que a criança busca a cada minuto de sua vida.

-- Makarenko, A colônia Gorki

\section{Cévennes, França, por volta de 1960}

Em 1955, Fernand Deligny, "o Makarenko francês" como o Partido Comunista Francês gostaria de promovê-lo, publicara um texto chamado "Caméra outil pédagogique", que se finalizava sobre as seguintes questões: em um mundo marcado pela força dos hábitos, da moda, dos costumes burgueses, força esta que impregnara tudo até a raiz, a começar pela própria linguagem, como criar o novo? Possivelmente através da imagem? Poderia o cinema escapar do modelo normativo e comunicativo da linguagem burguesa? 
No fim dos anos 1970 e no começo dos anos 1980, já bem longe de toda instituição e das pretensões do PCF, Deligny insiste na potência do cinema. Ele escreve uma série de textos intitulados Camérer. Trata-se de pensar o que poderia significar filmar, ou melhor, "camerar" em modo infinitivo, ou seja, sem a conjugação da pessoa: um filme sem sujeito e portanto sem objeto. Através desse verbo, Deligny procura frisar ao mesmo tempo o processo de filmagem e o aparelho (a câmera) como os elementos essenciais do cinema. Se não é o filme que interessa, então é preciso abandonar o verbo "filmar" e eleger um verbo que não se submeta ao produto final. A prática cinematográfica se voltaria então para o seu processo, para a "colheita" de imagens: buscar-se-ia não produzir imagens - l'image ne s'imagine pas, diz Deligny -, mas criar um contexto onde a imagem pode surgir - como que por inadvertência. Se as imagens não se imaginam, é porque, tal como em Benjamin, há uma precaução diante da passividade da imaginação. É preciso então pensar uma produção sem mestre, sem direção na qual a imagem possa surgir, como em um relampejar. Uma imagem sem objeto, não utilitária, não imaginada, não previamente concebida².

A reflexão de Deligny sobre a imagem nasce de seu interesse pelo cinema, mas igualmente de sua prática. No pós-guerra, o uso da câmera se torna central em seu trabalho na instituição La Grande Cordée - cujo presidente, Henri Wallon, escrevera o prefácio de uma edição francesa com textos de Makarenko. Mas somente em 1971, um primeiro filme de Deligny viria a ser finalizado: trata-se de Le moindre geste.

Le moindre geste não é exatamente um filme dirigido por Deligny. Entre 1962 e 1965, uma equipe registra o material usado para sua edição: Josée Manenti filma (com uma velha câmera Paillard de 16mm, que funciona com uma manivela), Guy Aubert grava à noite os discursos delirantes de Yves Guignard. O roteiro é escrito por Any Durand. Yves é um garoto autista considerado ineducável, um "débil profundo" confiado a Deligny em meados dos anos 1950. Deligny fabrica o campo objetivo: um projeto (e não um filme a realizar) no qual um cotidiano regrado seja tramado e a partir do qual um laço possa ser criado entre Yves e Deligny/Manenti. Deligny procura à noite dar indicações a Yves do que fazer, mas este obviamente não as segue e faz o que quer durante o dia. Durante esse período, mais de 20 horas de imagens são gravadas e o projeto é finalmente interrompido por falta de financiamento. As imagens só seriam montadas vários anos mais tarde, entre 1968 e 1970, por Jean-Pierre Daniel - que não se encontrava lá durante as filmagens. Manenti está sempre próxima a Yves, filmando-o de 
perto. Não há jamais retomada de cenas, os takes são únicos, e o filme se reinventa a cada dia em função dos lugares, da relação de Yves com espaço, as coisas e as pessoas que lá se encontram. A câmera se torna um instrumento que os conecta. O primeiro gesto é portanto o próprio ato de filmar. Jean-Pierre Daniel faz uma primeira montagem de 3h15m que é mostrada a Chris Marker. Este empresta então seu estúdio de montagem e de mixagem, recomenda o montador Jean-Pierre Rurh (que trabalhara, entre outros, com Éric Rohmer), que, por sua vez, se encarrega de captar novos sons (dos Cévennes, mas igualmente em manifestações na Argélia, na bolsa de Paris etc.) e o incita, nessa nova etapa, a jogar, a brincar com a montagem. Alguns meses mais tarde o filme encontra sua forma definitiva. O produto final surge assim quase que por inadvertência, mas após um longo trabalho e diversas etapas de fabricação.

Do que trata afinal o filme? Sua estrutura definitiva é bastante simples e se divide em três partes. Um primeiro momento que corresponde ao script inicial: Yves e Richard fogem de um asilo, Richard, em certo momento, cai em um buraco. A partir desse momento, começa a segunda parte, que é o coração do filme: Yves parece procurar rapidamente Richard, mas acaba por esquecê-lo e parte em uma errância nos Cévennes. Na terceira e última parte, com dez minutos de duração, Any reconduz Yves de volta ao asilo.

A matéria de Moindre Geste é o corpo de Yves que vaga e seu contato com os elementos do Cévennes, sua descoberta e experimentação desse espaço: pedras, rios, canteiros de obras, árvores, vilarejos... É todo um mundo do infinitamente pequeno no qual Yves se encontra imerso e no qual seus gestos afloram. Há uma interpenetração dos espaços do corpo de Yves, das coisas e da sua psyché, uma "comunidade das coisas" que a montagem procura traduzir ${ }^{3}$. O espaço das imagens é um espaço corporal e psíquico ${ }^{4}$. O discurso que acompanha o filme o faz não para narrar o espaço, não como uma legenda das imagens que viria descrevê-las, mas como uma força que as atravessa: o discurso de Yves não serve para comunicar suas sensações, mas é um discurso delirante que o atravessa. É aliás o que diz Deligny já no início do filme: "Yves é portador de uma palavra que não é dele, mas é preciso que a palavra pertença a alguém, mesmo que esse alguém a tome?" Yves no filme é o Yves cotidiano: um "débil profundo," "ineducável," que age de maneira incompreensível. O trabalho de montagem de Jean-Pierre Daniel respeita esse discurso delirante - palavra autista, cuja fonte é o simbólico perfurado - fazendo com que o discurso simplesmente atravesse as imagens, compondo-se com elas, sem no entanto parecer vir de Yves; desse modo, as imagens não reenviam mais 

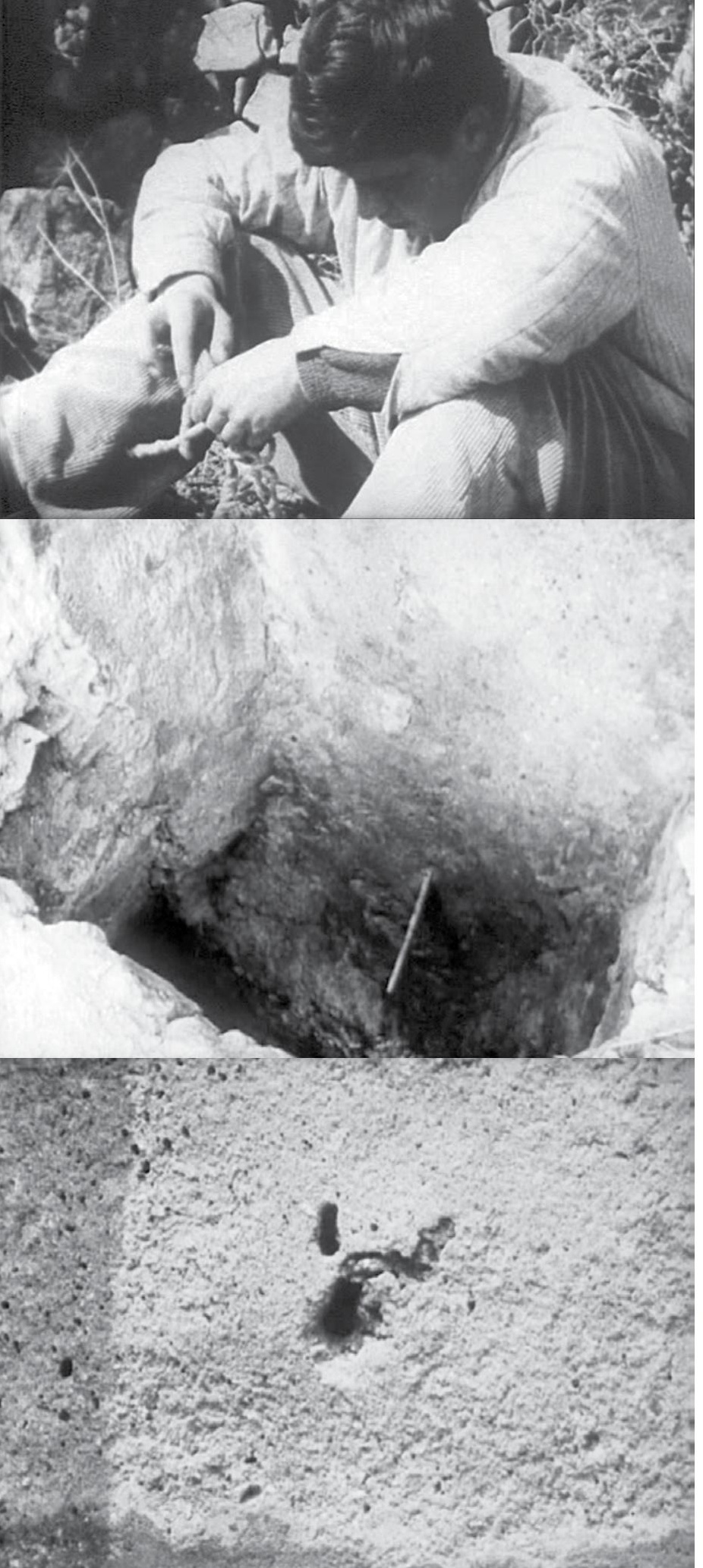

Imagens do filme Le moindre geste (1971) de Fernand Deligny / Josée Manenti 
a uma palavra precisa que as signifique. Estamos diante de imagens construtivas, imagens perfuradas - tais como Benjamin pensava no texto sobre a fotografia ${ }^{5}$. O discurso que atravessa Yves passa de rezas ou agradecimentos a delírios sobre De Gaulle; mas são também outros sons que vêm se compor a essa polifonia: vozes, bandas de rua ou militares, sons de um canteiro de obras, sons do rio, sons de árvores balançadas pelo vento, ecos de uma gota d'água. Yves é o nó, o emaranhado de todas essas linhas que o formam e o atravessam. A polifonia delirante se torna cada vez mais forte, alcançando seu auge na segunda parte do filme durante a errância de Yves.

Tal como o discurso de Yves que não significa um conteúdo preciso - não há intencionalidade em suas palavras -, as imagens não representam algo fora delas mesmas. Por isso Deligny falará de uma "imagem autista", imagem que não diz nada, que reenvia a si mesma. Trata-se assim de um cinema documentário impelido ao seu limite, construído fora do sentido dado, das palavras, e aberto à pura presença de matérias e corpos. Mas estaríamos realmente no documentário, ou antes na ficção? O começo do filme já brinca com essa questão: temos uma imagem de um jornal que noticia a fuga de um boi do abatedouro e sua queda em um buraco próximo à Gare de l'Est - e qual a correspondência entre o abatedouro e o asilo? Não seria essa uma das questões-chave da tentativa de Deligny? Em seguida, temos a apresentação dos "atores" / "personagens": alguns atores representam "eles mesmos" (Yves est Yves), outros não, encenando personagens (La mere d'Any est la mère de Richard).

O campo objetivo fabricado por Deligny é um Spielraum. O jogo, a brincadeira, está presente desde a relação estabelecida entre Manenti e Yves através da câmera até a montagem, passando ainda pela relação entre Yves e as coisas descobertas por ele em sua errância. Esse campo foi a forma encontrada pela qual imagens pudessem surgir e uma tradução da psyché e dos gestos de Yves pudesse ser feita. Pois como representar esses gestos mínimos, gestos desprovidos de sentido dado sem procurar antecipá-los para assim explicá-los? O gesto mínimo é um gesto não intencional, gesto sem projeto que não visa realizar algo - geste pour rien. São gestos, como em uma brincadeira, que não reenviam a outra coisa senão a eles mesmos. O gesto é mínimo, segundo Deligny, pois falta o elo entre essa ação e uma outra, ou entre essa ação e um objetivo visado. Por isso temos a impressão de estarmos diante de gestos inacabados, não concatenados, sem objetivo, nem projeto. 
A esse gesto que parece inacabado, pois ele parece sem objeto nem projeto, o que lhe falta, a esse gesto, é o que lhe foi mutilado, e é igualmente o que nos falta, o que nós carecemos; isso que nos falta, e talvez de maneira irreversível pelo fato que cada um se mobiliza - e como é louco como ele o faz - pela sua identidade pessoal. E de tanto se mobilizar, ele está agora imobilizado: este "ele" que nós somos, é "eu" que ali se encontra, nas mãos de Deus, imobilizado em, mobilizado por... (DELIGNY, 2007, p. 763)

O filme "acabado" procura traduzir em sua forma mesma esse gesto desprovido de sentido. As imagens não servem para reconhecer o gesto de Yves, mas são o meio de descobri-lo, fabricando-o - por isso são imagens furadas, esburacadas. É preciso notar entretanto que se as imagens não exprimem algo exterior a elas, se elas não possuem então um significado, elas são no entanto significantes. Para que a montagem consiga produzir algo, é preciso que ela construa, ou melhor, costure uma trama significante. Ou como dizia Benjamin acerca da tradução, é preciso fazer do simbolizante o simbolizado para que assim se possa liberar o sentido (BENJAMIN, 2000a, p. 258-259), ou em termos mais modernos, fazer do significante o próprio significado da imagem. Em Le moindre geste há justamente uma série de imagens que constitui a linha do filme, que intervém de maneira contínua como intervalos à errância de Yves: trata-se dos nós do cadarço que ele busca incessantemente enlaçar (tradução do gesto inacabado), dos buracos e dos furos na parede (tradução da imagem furada e autista), das casas em ruínas e sem telhado (tradução da psyché autista: sans toilt) ni moi ["sem você/ teto nem eu"]). Dentre um imenso material, certas imagens foram escolhidas como imagens-tema, imagens que vêm pontuar a trama de imagens. A trama de imagens não é a montagem encadeada de um pensamento ou de um discurso coerente e linear, mas uma trama de linhas de erro (as lignes d'erre sobre as quais Deligny fala em seu projeto cartográfico).

A verdadeira origem da linguagem, Benjamin não cansou de insistir sobre esse ponto em seus primeiros textos, é a linguagem poética, o "momento falante (ou significante) da linguagem", como diria Henri Maldiney acerca de Moindre Geste. (DELIGNY, 2007b, 14min.) No texto de 1916 acerca da linguagem, Benjamin já falava da relação originária e fundamental entre linguagem e signo. (BENJAMIN, 2000a, p. 164) Essa relação não seria a do signo enquanto sinal, sinalização de um espaço desconhecido e novo para além da linguagem conhecida? Tanto Deligny quanto Benjamin confrontam essa mesma linguagem burguesa que veicula conteúdos já conhecidos, repetindo-os e reafirmando-os, de forma ideológica. O texto de 


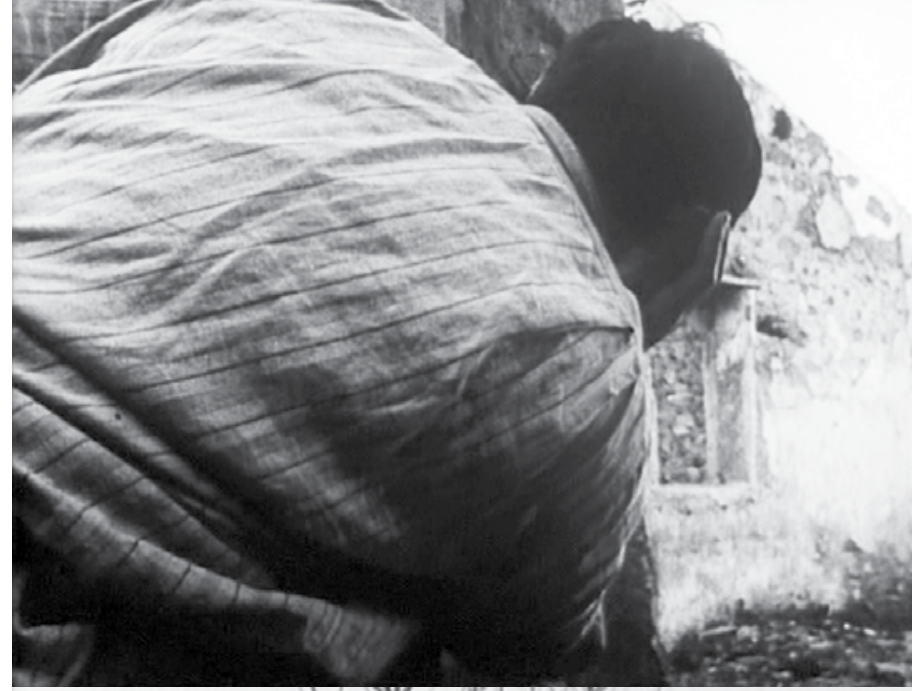


Benjamin procurava, com o conceito de expressão, justamente atacar esse modelo de linguagem comunicativa e reificadora. A linguagem sendo expressiva almeja em sua potência máxima o sem-expressão. Mas este nada tem a ver com o inexprimível: o sem-expressão é de certo modo o que tudo diz, o nível mais alto da expressividade, do que é exprimível. Nesse nível, a linguagem pode ser expressão do não-comunicável. (BENJAMIN, 2000a, p. 164-165) A pesquisa de Deligny, como este não cansa de afirmar, é sobre o ponto de ver e não sobre o ponto de vista autista. Esse deslocamento implica no abandono do registro de um sujeito que reproduz constantemente a si mesmo em suas obras. Assumir então o ponto de ver autista não seria o esforço de traduzir na imagem esse modo de "ver sem querer ver"? Graças à imagem, esse ponto não-comunicável da criança autista - esse ponto de ver-, que não é completamente experimentável para o espectador, pode aparecer e ser expresso.

O cinema aparece aqui como o suporte privilegiado de uma operação: tradução da não-língua autista na língua das imagens. E se a tradução deve, como aponta Benjamin na "Tarefa do tradutor", afrontar o sentido, sem procurar escondê-lo, eclipsá-lo, mas tampouco restituí-lo de forma fiel (BENJAMIN, 2000a, p. 257), não seria através de uma sintaxe não comunicativa das imagens que a psyché autista poderia ser traduzida? Se faz parte da potência mimética da linguagem produzir semelhanças não-sensíveis através de um suporte, não seria justamente a imagem o suporte por excelência para uma apresentação (Darstellung) do ponto de ver? Le moindre geste é assim a tentativa de se fabricar uma fisionomia do autismo por intermédio da imagem, de modo que se poderia pôr em relação o "Was nie geschrieben wurde lesen" benjaminiano com "voir ce qui ne peut pas se voir" deligniano.

Le moindre geste, buscando a ausência de comunicação da palavra autista, acaba por abrir passagem ao que Benjamin chamava de "linguagem pura", lá onde não há mais nenhuma instrumentalização, mas pura palavra criadora. A sintaxe da montagem é a tradução da sintaxe de uma palavra confusa que atravessa Yves, e tal tradução é reveladora de algo essencialmente humano. Esse algo essencial, muitas vezes escondido pela verborragia do homem "normal", pode ser, no entanto, reencontrado e diz respeito à intuição benjaminiana acerca da linguagem pura. O próprio Benjamin o percebera quando, no fim do texto sobre a sociologia da linguagem, citando o trabalho de Kurt Goldstein sobre a afasia, reafirma, uma vez mais, a linguagem não como um instrumento, mas como um modo humano de estabelecer relações 
vivas, como uma manifestação essencial da ligação psicológica que nos liga a nós mesmos e nossos semelhantes. (BENJAMIN, 1991c, p. 480) Benjamin avança nesse texto duas teses importantes e pouco consideradas pelos comentadores: 1. o gesto é primeiro em relação ao som, à palavra; 2. o estudo de patologias pode nos fazer redescobrir elementos essenciais do humano. Como na tentativa de Deligny, não se trata de modo algum de fazer um elogio pueril e idealista do autismo ou de outras patologias, mas de ver que elementos essencialmente humanos podem aparecer através dessas patologias. Tais patologias, por conta de um retardo ou de um mal desenvolvimento, possibilitariam que outras camadas, mais dificilmente percebidas no "homem normal", venham à tona e sejam reconhecidas. A imagem autista, no caso de Deligny, nos ensina assim um modo de ser outro que pode ser descoberto através da tradução na imagem. A partir daí, há dissociação entre o aspecto puramente patológico do autismo e um estado estético autista. Se o autismo é a falha da estruturação simbólica e portanto da função sujeito, da função da palavra comunicativo-dialógica, da unificação sensorial, da divisão do eu causando uma imersão do indivíduo no real e no mundo das coisas, nos abrimos então a uma significação profunda de diversos novos elementos: o mimetismo do individuo face às coisas, a ausência de significação e de utilidade do gesto e da palavra. Nos abrimos à irredutibilidade mesma do gesto, em seu minimalismo, e antes de todo enclausuramento em uma significação definitiva.

\section{Notas}

1 Sobre o jogo, ver também Brèves Ombres, II, Jeu (in BENJAMIN, 2000b).

2 Esta questão acerca do modo de produção da obra de arte já era central para Benjamin. No texto O autor como produtor, referindo-se a Bertold Brecht, ele trata da importância de se pensar uma nova relação, não burguesa, ou seja coletiva, na criação artística

3 No texto de 1916 sobre a linguagem, Benjamin fala que no registro de linguagem das coisas, essas se encontram em uma "comunidade material". (BENJAMIN 2000a, p. 164) A linguagem do homem vem arrancar as coisas do seu mutismo. Seria igualmente interessante analisar a relação mimética que Yves estabelece com as coisas - p.e. como ele balança e parece se tornar um com uma escavadeira, quando, em certo momento de sua errância, passa por um canteiro de obras. Como diz Benjamin em seu texto acerca do poder de imitação "na dança, em outras cerimônias cultuais, podia-se produzir uma imitação, pôr em obra uma semelhança". (BENJAMIN 2000b, p. 360)

4 Benjamin já havia notado acerca do surrealismo essa interpenetração possível entre espaço de imagem, espaço corporal e espaço coletivo. (BENJAMIN, 2000b, p. 134) 
5 A fotografia em Benjamin possui uma potência de pontuação e ela fabrica imagens furadas. Essas imagens são impressão do real (Wirklichkeit) e escapam ao sujeito que as quer produzir. Há algo na imagem que escapa e que as perfura (Benjamin utiliza o verbo durchsengen, como algo que queima perfurando).

\section{Referências}

BENJAMIN, Walter. Gesammelte Schriften Bd.2. Frankfurt: Suhrkamp, 1991a.

BENJAMIN, Walter. Gesammelte Schriften Bd.4. Frankfurt: Suhrkamp, 1991b.

BENJAMIN, Walter. Gesammelte Schriften Bd.3. Frankfurt: Suhrkamp, 1991c.

BENJAMIN, Walter. Écrits Français. Paris: Gallimard, 1993.

BENJAMIN, Walter. CEuvres I. Paris: Gallimard, 2000a

BENJAMIN, Walter. CEuvres /I. Paris: Gallimard, 2000b.

BENJAMIN, Walter. CEuvres III. Paris: Gallimard, 2000c.

DELIGNY, Fernand. CEuvres. Paris: Éditions de I'Arachnéen, 2007a.

DELIGNY, Fernand. Le cinéma de Fernand Deligny (DVD). Paris: Éditions Montparnasse, 2007b.

LÉZINE, Irène. A. S. Makarenko, Pédagogue soviétique (1888-1939). Paris: PUF, 1954

TACKELS, Bruno. L'oeuvre d'art à l'époque de W. Benjamin. Paris: L'Harmattan, 2000. 